\title{
THEODORE DRU ADDISON COCKERELL
}

As this issue of Psyche goes to press, we have received notice of the death of Professor T. D. A. Cockerell on January 26, 1948. The following sketch of his life is presented as a tribute and in recognition of his entomological contributions. The accompanying photograph was kindly sent by Dr. Norma LeVeque.

Born in Norwood, England, in 1866, Professor Cockerell came to this country at the age of twenty-one and for the last forty-four years of his life was on the faculty of the University of Colorado. He made many collecting trips, even to such remote places as India, Australia, Peru, Siberia, and South Africa. His interests in natural history were very broad and his publications, which number over three thousand, include contributions to botany, paleontology, and zoology. Insects, of course, were his main interest. His early investigations were on Lepidoptera, scale insects and Hymenoptera. If he had a specialty, it was the taxonomy of the wild bees. While at the University of Colorado, he worked extensively on insects in the Florissant Shales, which were not far from Boulder. He also published many papers on fossil insects in the Green River Shales, the ironstone nodules of Illinois, the coal beds of Maryland, the Baltic amber, and several other deposits. He was a regular contributor to Psyche. His first paper in this journal, on Jamaican butterflies, appeared in 1893 (vol. 6) ; the last, on African bees, in 1946.

Professor Cockerell was an inspiring teacher. His wide knowledge and boundless enthusiasm attracted students to the University of Colorado from remote parts of the country. That many of these have become outstanding zoologists and entomologists is due in large measure to the unique abilities of their teacher.

The Editorial Board. 


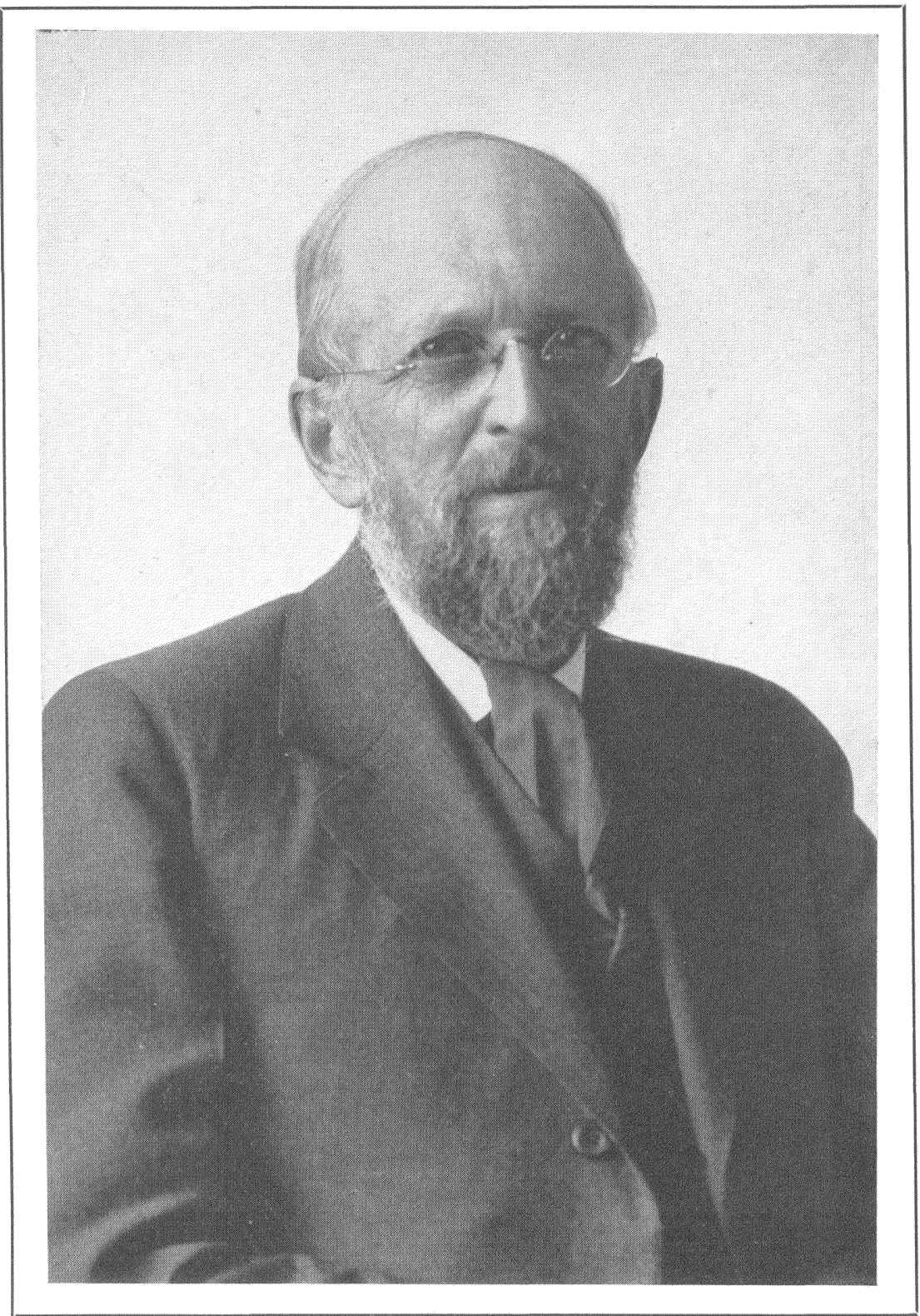

Theodore Dru Addison Cockerell 

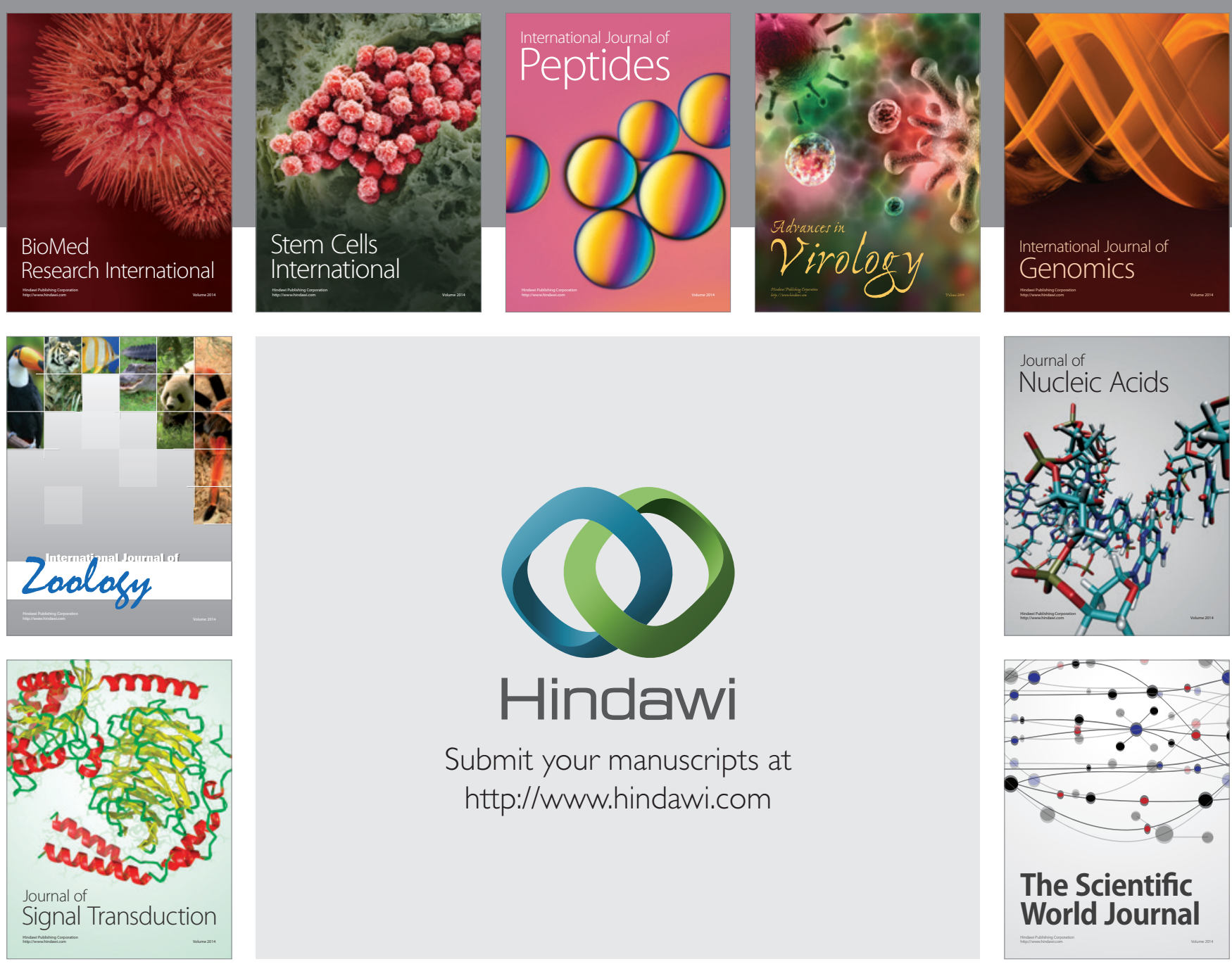

Submit your manuscripts at

http://www.hindawi.com
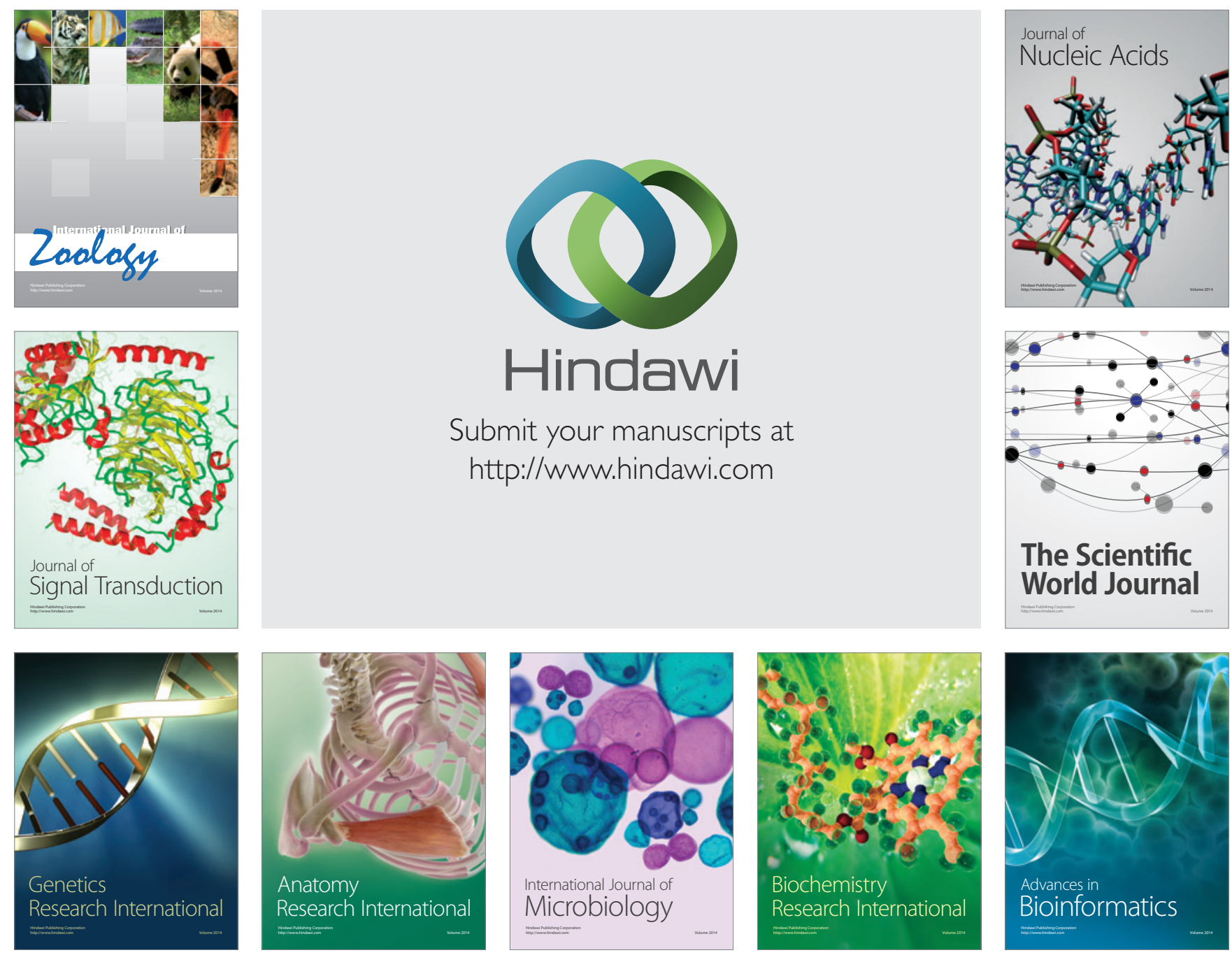

The Scientific World Journal
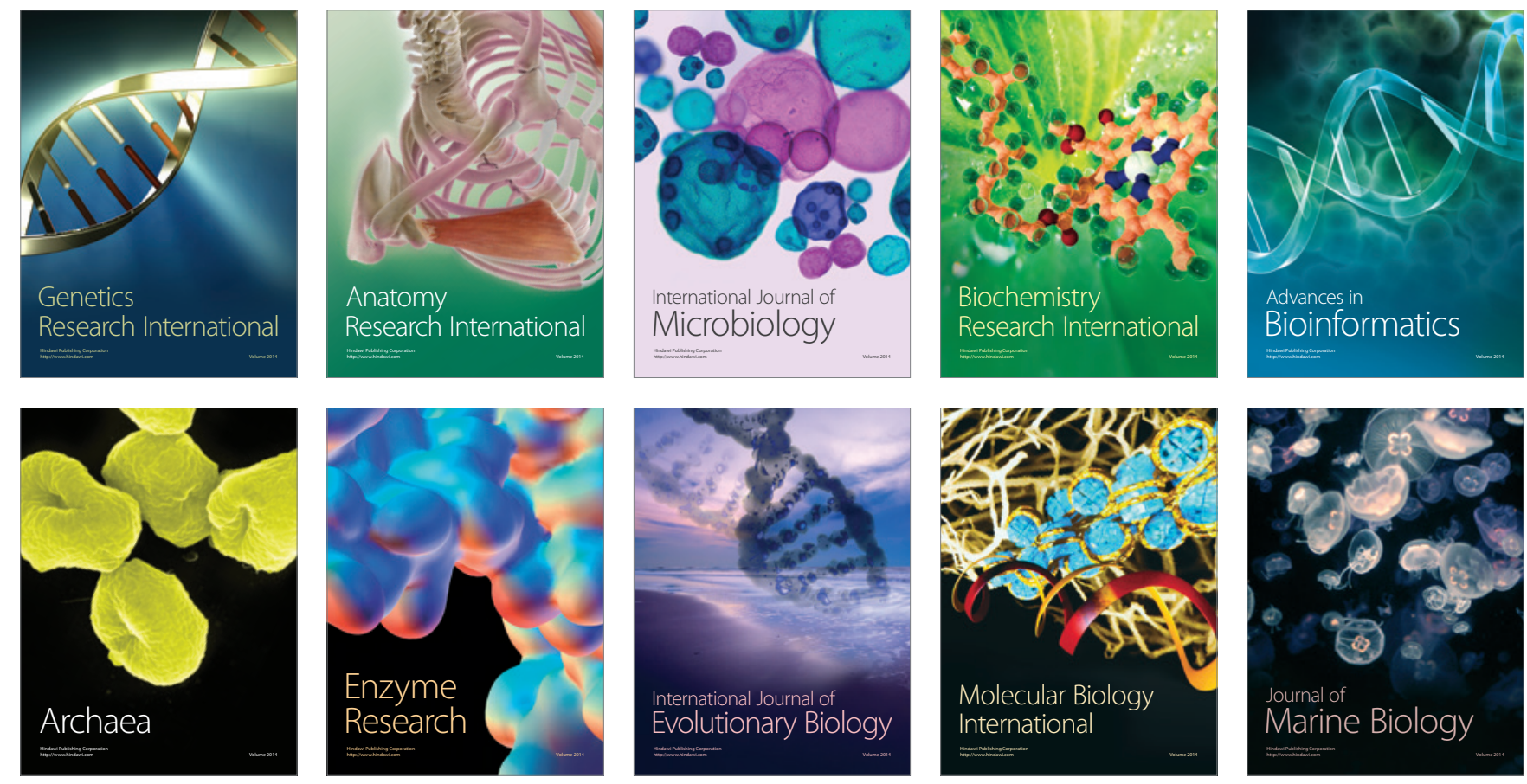